\title{
Effect of a mixture of micronutrients, but not of bovine colostrum concentrate, on immune function parameters in healthy volunteers: a randomized placebo-controlled study Danielle AW Wolvers*, Wendy MR van Herpen-Broekmans, Margot HGM Logman, Reggy PJ van der Wielen and Ruud Albers
}

Address: Unilever Food \& Health Research Institute, Olivier van Noortlaan 120, NL-3133 AT, Vlaardingen, The Netherlands

Email: Danielle AW Wolvers* - danielle.wolvers@unilever.com; Wendy MR van Herpen-Broekmans - wendy-van.herpen@unilever.com; Margot HGM Logman - margot.logman@unilever.com; Reggy PJ van der Wielen - reggy-van-der.wielen@unilever.com;

Ruud Albers - ruud.albers@unilever.com

* Corresponding author

Published: 2I November 2006

Nutrition Journal 2006, 5:28 doi:10.1 186/1475-289/-5-28

This article is available from: http://www.nutritionj.com/content/5/I/28

(c) 2006 Wolvers et al; licensee BioMed Central Ltd.

This is an Open Access article distributed under the terms of the Creative Commons Attribution License (http://creativecommons.org/licenses/by/2.0), which permits unrestricted use, distribution, and reproduction in any medium, provided the original work is properly cited.

\begin{abstract}
Background: Supplementation of nutritional deficiencies helps to improve immune function and resistance to infections in malnourished subjects. However, the suggested benefits of dietary supplementation for immune function in healthy well nourished subjects is less clear. Among the food constituents frequently associated with beneficial effects on immune function are micronutrients such as vitamin $\mathrm{C}$, vitamin $\mathrm{E}, \beta$-carotene and zinc, and colostrum. This study was designed to investigate the effects these ingredients on immune function markers in healthy volunteers.
\end{abstract}

Methods: In a double-blind, randomized, parallel, $2 * 2$, placebo-controlled intervention study one hundred thirty-eight healthy volunteers aged 40-80 y (average $57 \pm 10$ y) received one of the following treatments: (I) bovine colostrum concentrate $1.2 \mathrm{~g} / \mathrm{d}$ (equivalent to $\sim 500 \mathrm{mg} / \mathrm{d}$ immunoglobulins), (2) micronutrient mix of $288 \mathrm{mg}$ vitamin E, $375 \mathrm{mg}$ vitamin C, $12 \mathrm{mg} \beta$-carotene and $15 \mathrm{mg}$ zinc/day, (3) combination of colostrum and micronutrient mix, or (4) placebo. Several immune function parameters were assessed after 6 and 10 weeks. Data were analyzed by analysis of variance. Groups were combined to test micronutrient treatment versus no micronutrient treatment, and colostrum treatment versus no colostrum treatment.

Results: Overall, consumption of the micronutrient mix significantly enhanced delayed-type hypersensitivity (DTH) responses $(p<0.05)$. Adjusted covariance analysis showed a positive association between DTH and age. Separate analysis of younger and older age groups indicated that it was the older population that benefited from micronutrient consumption. The other immune function parameters including responses to systemic tetanus and oral typhoid vaccination, phagocytosis, oxidative burst, lymphocyte proliferation and lymphocyte subset distribution were neither affected by the consumption of micronutrients nor by the consumption of bovine colostrum concentrate.

Conclusion: Consumption of bovine colostrum had no effect on any of the immune parameters assessed. The micronutrient mix enhanced cellular immunity as measured by DTH, with an increased effect by incremental age, but did not affect any of the other immune parameters measured. Although correlations between decreased DTH and enhanced risk of certain infection have been reported, it remains unclear whether and enhanced DTH response actually improves immune defense. The present data suggests that improvement of immune parameters in a population with a generally good immune and nutritional status is limited and that improvement of immune function in this population may be difficult. 


\section{Background}

Supplementation of nutritional deficiencies helps to restore immune function and contributes to increased resistance to infections in malnourished subjects [1]. The literature is less clear however, on the suggested benefits of dietary supplementation for immune function in healthy well nourished subjects without overt signs of compromised immune function. Still, there is strong interest among consumers for food products that can help optimize their immune system and numerous products claiming this, are on the market. Among the food constituents frequently associated with beneficial effects on immune function are micronutrients such as vitamin $\mathrm{C}$, vitamin $\mathrm{E}, \beta$-carotene and zinc, and also the first milk produced after parturition (colostrum).

Studies suggest that vitamin C may enhance immune functions such as phagocytosis, neutrophil chemotaxis and lymphocyte proliferation [2-4], but contrasting findings have also been published [5-7].

Vitamin E has been shown to enhance antibody responses to hepatitis B- and tetanus vaccination [8] and to increase delayed type hypersensitivity (DTH) response in healthy elderly people $[8,9]$, $\beta$-carotene can affect immune function after conversion to vitamin A, but also influences immune activity beyond its pro-vitamin A activity [10]. The most consistent findings of $\beta$-carotene activity on immune function are enhanced NK cell activity and TNF$\alpha$ production [11-13]. Supplementation with 15-25 mg zinc per day in elderly people showed no improvement of the DTH response, lymphocyte proliferation or NK cell activity [14-16]. Higher doses (> $100 \mathrm{mg} /$ day) may improve certain immune aspects in elderly, although some findings are controversial $[14,17,18]$.

Colostrum contains high concentrations of natural immunoglobulins (mainly IgG) that can bind and neutralize pathogens in the intestinal tract, bactericidal factors such as lactoferrin, lactoperoxidase and lysozyme, and growth factors and cytokines that may improve immune defense and gut-barrier function [19-21]. However, data to substantiate suggested benefits of natural colostrum are limited. Natural bovine colostrum has been shown to stimulate in vitro phagocytic activity of leukocytes from cattle [22] and human [23]. Consumption of $100 \mathrm{ml}$ colostrum daily for 7 days by volunteers that were orally vaccinated to S.typhi, resulted in more volunteers with a high number of specific IgA secreting cells, although the average number of specific antibody secreting cells was not increased [24].

The current study was designed to investigate the efficacy of commercially viable- and "realistically-to-consume amounts" of bovine colostrum concentrate (Proventra ${ }^{\circledR}$ ) and a mix of micronutrients (vitamins $\mathrm{E} \& \mathrm{C}, \beta$-carotene and zinc) on immune function in healthy immuno-competent subjects aged $40-80 \mathrm{y}$. Using a complete $2 * 2$ factorial design, subjects were supplemented with bovine colostrum, a mixture of the micronutrients, a combination of bovine colostrum and micronutrients, or a placebo, for 10 weeks. A range of immunological markers was measured, which were identified as relevant for assessing immune function and comprised aspects of innate and adaptive immune function [25]. These included the response to tetanus and (oral) typhoid vaccination, delayed-type hypersensitivity (DTH) responses, phagocytosis, oxidative burst, lymphocyte proliferation and lymphocyte subset distribution.

\section{Methods \\ Subjects and study design}

This study was conducted from September to December 2001 at the Unilever Food \& Health Research Institute, Vlaardingen, The Netherlands, after approval by the Medical Ethical Committee of Unilever R\&D Vlaardingen. At an oral briefing 394 interested candidates completed a questionnaire, resulting in 110 rejections based on exclusion criteria and 21 withdrawals. Two hundred and sixtythree subjects were invited for physical examination. One hundred seventy seven subjects were found eligible. Two subjects withdrew and 35 were excluded by lot. The remaining 140 subjects were randomized to the treatments. Three subjects withdrew after randomization but before the start of the study. One subject was replaced. Finally, one hundred and thirty-eight subjects entered the study. Subjects were healthy, non-smoking, males and females $40-80$ y of age, with average Dutch dietary habits, $\mathrm{BMI} \geq 18,0<32,0 \mathrm{~kg} / \mathrm{m}^{2}$, normal clinical chemistry, tetanus antibody titers $<700 \mathrm{IU} / \mathrm{L}$, and plasma vitamin E levels $\leq 40 \mu \mathrm{mol} / \mathrm{L}$. Exclusion criteria were: known diseases, medication affecting immune function and/or intestinal flora, lactose intolerance, high IgE titers to bovine milk or prior typhus vaccination. Subjects were allocated to one of four treatment groups, stratified for gender and randomized for age, basal plasma vitamin E concentrations and titer of tetanus antibodies.

Using a complete $2 * 2$ factorial design, subjects received: (1) control product (2) product containing $1.2 \mathrm{~g} / \mathrm{d}$ bovine colostrum concentrate (equivalent to $430 \mathrm{mg}$ IgG), (3) a product containing a mix of micronutrients or (4) a product containing both the bovine colostrum concentrate and the micronutrient mix. The active ingredients were supplied in single serving sachets containing powdered drinks based on skim milk powder, sugar and maltrodextrin. Other ingredients were citric acid, lecithin, colorant and flavoring. The levels of active ingredients are listed in Table 1. Bovine colostrum concentrate (Proventra ${ }^{\circledR}$ ) was obtained from GalaGen Inc.(Minnetonka MN) as a spray 
dried sterile filterable powder from the whey fraction of non-specific bovine colostrum. The formulation was developed at the Unilever Health Institute and produced at Budelpack Hamont N.V./S.A. (Hamont-Achel, Belgium). Participants were asked to consume one serving of water-soluble powder dissolved in a glass of water $(100$ $\mathrm{ml}$ ) at breakfast and one at dinner. The control and test products were supplied to the participants (pre-portioned in $20 \mathrm{~g}$ amounts in two flavors) every 2 weeks. Compliance to dietary restrictions and test product consumption was evaluated at 2 week intervals using a questionnaire.

Participants were instructed to maintain their habitual diet and refrain from using supplements containing vitamin $\mathrm{E}$, vitamin $\mathrm{C}$, $\beta$-carotene, zinc, pre- and probiotics and supplements claiming to affect immune function or gut health. Before the intervention, baseline measures were taken of plasma micronutrient concentrations, DTH response, vaccine-specific antibodies and ex vivo immune functions (leukocyte subsets, phagocytosis, oxidative burst, lymphocyte proliferation, cytokine production). These measures were repeated after 6 weeks intervention. Subsequently, subjects received an intra-muscular tetanus vaccine and an oral typhoid vaccine. The dietary intervention was continued until week 10 and specific responses to the vaccines were measured in week 8 and 10. In addition, a final measurement of the plasma concentrations of vitamin $\mathrm{E}$, and $\mathrm{C}$, and $\beta$-carotene was made at week 10 .

\section{Blood and saliva sampling}

Fasted blood samples were obtained at baseline, week 6, week 8 and week 10 by venipuncture. Aliquots of plasma and serum were stored at $-70^{\circ} \mathrm{C}$ until further analysis. Plasma for vitamin $\mathrm{C}$ analysis was mixed with metaphosphoric acid and stored at $-20^{\circ} \mathrm{C}$. Saliva stimulated by chewing on parafilm was collected at baseline, week 8 and week 10. Samples were kept on ice, centrifuged 15 minutes at $3000 \mathrm{~g}$ at $4{ }^{\circ} \mathrm{C}$ to pellet debris. Supernatants were aliquoted and stored at $-70^{\circ} \mathrm{C}$ until further analysis.

\section{Vaccination}

After 6 weeks, subjects were vaccinated for tetanus (single i.m. injection of tetanus toxoid vaccine, Te Anatoxal Berna, Primmed BV, Almere, NL) and typhoid (three oral doses on alternate days of Vivotif Berna, Primmed BV, Almere, NL), to assess both systemic and mucosal immune responses. Vaccine-specific antibodies were determined at baseline and weeks 8 and 10 (i.e. 2 and 4 weeks after vaccination). Proliferative responses to the vaccine antigen were determined at baseline and week 10 . Tetanus specific antibody titers were determined by ELISA (Tetanus toxoid Sensitive IgG antibody test, Gamma Angleur-Liege, Belgium) according to manufacturer's instructions. Subjects with $\geq 4$-fold increase over baseline were classified as responders to the tetanus vaccination. Antibodies to S.typhi Ty21a LPS were determined by ELISA at the Berna Swiss Serum and Vaccine Institute, Berne, Switzerland according to a standard operating procedure. Sub-

Table I: Composition of study products'. Content of the study products was determined at baseline and for micronutrients $\mathrm{E}$ and $\mathrm{C}$ and $\beta$-carotene also at week 6 and week 10 . Of each group, both mango- and orange flavored products were analyzed. Data are presented as the contents of 2 packages, which represents a daily dose.

\begin{tabular}{|c|c|c|c|c|c|c|c|c|c|}
\hline & \multirow[b]{2}{*}{ target } & \multicolumn{2}{|c|}{ Control } & \multicolumn{2}{|c|}{ Colostrum } & \multicolumn{2}{|c|}{ Micronutrients } & \multicolumn{2}{|c|}{ Colostrum + Micronutrients } \\
\hline & & orange & mango & orange & mango & orange & mango & orange & mango \\
\hline Energy* (kJ) & & 628 & 627 & 626 & 625 & 625 & 624 & 623 & 622 \\
\hline Moisture (\%)* & & $2.6 \pm 0.1$ & $2.25 \pm 0.25$ & $2.65 \pm 0.15$ & $3.15 \pm 0.25$ & $2.3 \pm 0.1$ & $2.5 \pm 0.2$ & $3.1 \pm 0.1$ & $3.1 \pm 0.1$ \\
\hline Fat $(\%)^{*}$ & & $5.5 \pm 0.1$ & $5.45 \pm 0.05$ & $5.5 \pm 0.1$ & $5.9 \pm 0.3$ & $6.2 \pm 0$ & $6.4 \pm 0.1$ & $6.6 \vee 0.2$ & $6.2 \pm 0$ \\
\hline Protein $(\%)^{*}$ & & $17.3 \pm 0.1$ & $17.6 \pm 0.1$ & $16.9 \pm 0.1$ & $17.1 \pm 0.25$ & $17.1 \pm 0.2$ & $16.9 \pm 0.15$ & $16.9 \pm 0.15$ & $17.2 \pm 0.3$ \\
\hline $\lg G(m g) * 2$ & & - & - & 422 & 466 & - & - & 430 & 416 \\
\hline \multicolumn{10}{|l|}{ Vitamin E (mg) } \\
\hline Baseline & 200 & - & - & - & - & $333 \pm 8$ & $314 \pm 1.4$ & $296 \pm 8.8$ & $293 \pm 1$ \\
\hline week 6 & & - & - & - & - & $272 \pm 2.7$ & $278 \pm 4.2$ & $268 \pm 0.5$ & $264 \pm 0.3$ \\
\hline week 10 & & - & - & - & - & $281 \pm 0.3$ & $279 \pm 2.8$ & $290 \pm 0.8$ & $286 \pm 0.2$ \\
\hline \multicolumn{10}{|l|}{$\beta$-carotene $(\mathrm{mg})$} \\
\hline Baseline & 10 & - & - & - & - & $12.6 \pm 0.2$ & $13.2 \pm 0.5$ & $12.3 \pm 0.4$ & $12.2 \pm 0.4$ \\
\hline week 6 & & - & - & - & - & $11.0 \pm 0$ & $10.8 \pm 0.2$ & $11.2 \pm 0,2$ & $10.8 \pm 0.4$ \\
\hline week 10 & & - & - & - & - & $12.7 \pm 0.4$ & $12.9 \pm 0.1$ & $12.6 \pm 0.2$ & $12.1 \pm 0.2$ \\
\hline \multicolumn{10}{|l|}{ Vitamin C (mg) } \\
\hline Baseline & 250 & - & - & - & - & $365 \pm 8$ & $351 \pm 6$ & $369 \pm 6$ & $385 \pm 10$ \\
\hline week 6 & & - & - & - & - & $395 \pm 15$ & $381 \pm 4$ & $364 \pm 17$ & $345 \pm 27$ \\
\hline week 10 & & - & - & - & - & $382 \pm 6$ & $386 \pm 4$ & $382 \pm 5$ & $390 \pm 3$ \\
\hline Zinc (mg) * & 15 & - & - & - & - & $14.6 \pm 2.04$ & $15.3 \pm 1.83$ & $15.09 \pm 0.3$ & $16.04 \pm 1.28$ \\
\hline
\end{tabular}

* parameters identified by * were determined at baseline only. - not determined.

I data are expressed as mean \pm SD, except for (calculated) energy and IgG, which are given as means.

${ }^{2} \mathrm{ggG}$ was determined by radioimmunodiffusion by Galagen Inc. Mean concentrations of 2 tests were reported without SD. 
jects with $\geq$ 2-fold increase over baseline for postvaccination titers $>1 \mathrm{E} . \mathrm{U} / \mathrm{ml}$, or $\geq 3$-fold increase over baseline for postvaccination titers $<1 \mathrm{E} . \mathrm{U} / \mathrm{ml}$ were classified as responders [26] (Dr.J. Que, Swiss Vaccine Institute, personal communication)

\section{Delayed-type hypersensitivity (DTH) response}

Delayed-type recall responses were assessed at baseline and after 6 weeks intervention using the Multitest CMI applicator from Pasteur Mérieux (Lyon, France) for simultaneous intra-cutaneous application of six antigens (Tetanus, Diphteria, Streptococcus group C, Candida albicans, Trichophyton mentagrophytes, Proteus mirabilis). Tuberculin was removed from the applicator to avoid interference with tuberculosis surveillance. Forty-eight \pm 3 hours after application, the number of indurations and induration diameters were recorded. The DTH response of each subject was calculated as the number of positive $(>2 \mathrm{~mm}$ ) responses out of the six test antigens and the sum of diameters of all positive responses.

\section{Plasma levels of micronutrients}

Micronutrient concentrations were determined in plasma samples collected at baseline, week 6 and week 10. $\alpha$ Tocopherol and $\beta$-carotene levels were determined by HPLC, performed at Analytico Medinet B.V (Breda, Netherlands) according to standard procedures. Vitamin $\mathrm{C}$ was determined enzymatically on EDTA plasma samples (stored frozen with $4.5 \% \mathrm{MPA}$ ) according to Vuilleumier and Keck (1989) adapted for use on a Packard Multiprobe ll HT analyzer.

\section{Leukocyte subsets}

Leukocyte subsets were determined in heparinized whole blood at baseline, week 6 and week 10 using a standardized four-color flowcytometric method (TetraCHROME, Beckman Coulter Nederland BV, Mijdrecht with added CD16-RD1 from Immunotech). Absolute numbers and percentages of leukocytes (CD45+), T cells (CD45+/ $\mathrm{CD} 3+)$, helper $\mathrm{T}$ cells (CD3+/CD4+/CD45+), cytotoxic/ suppressor $\mathrm{T}$ cells $(\mathrm{CD} 3+/ \mathrm{CD} 8+/ \mathrm{CD} 45+)$, precursor $\mathrm{B}$ cells and B cells (CD19+/CD45+) and NK cells (CD3-/ (CD56/CD16)+/CD45+) were determined. Samples were analyzed on the Coulter EPICS XL flowcytometer (Beckman Coulter Nederland BV, Mijdrecht) using fully automated tetraONE SYSTEM software (Beckman Coulter Nederland BV, Mijdrecht).

\section{Phagocytosis and oxidative burst}

Phagocytic activity and oxidative burst were determined in heparinized whole blood at baseline and week 6 . For phagocytosis, $50 \mathrm{ul}$ of whole blood was incubated at $37^{\circ} \mathrm{C}$ for 5 minutes with FITC-labeled E.coli (Phagotest ${ }^{\oplus}$, Orpegen, Heidelberg, Germany), or for 10 minutes with unlabeled E.coli (Phagoburst ${ }^{\oplus}$, Orpegen, Heidelberg, Ger- many) according to the manufacturers instructions. Control samples were incubated with bacteria on ice. For oxidative burst, samples were subsequently incubated with dihydrorhodamine 123 substrate for 10 minutes. For both assays erythrocytes were lysed and samples were fixed and stained with propidium iodide. Analysis was performed by flowcytometry (Coulter EPICS XL, Beckman Coulter Nederland BV, Mijdrecht). Leukocytes were gated into monocyte and granulocyte populations according to FSC/SSC profile. The percentage of cells responding with phagocytosis/oxidative burst in these populations and the mean fluorescence of these cells were determined.

\section{Lymphocyte proliferation}

Mitogen-induced lymphocyte proliferation was assessed in $10^{*}$ diluted whole blood cultures at baseline and week 6 . Samples were incubated in quadruplicate with a mixture of anti-CD3 and anti-CD28 monoclonal antibodies (PeliCluster, Sanquin Reagents, Amsterdam, the Netherlands) at final concentrations of $0,0.1$ and $1 \mu \mathrm{g} / \mathrm{ml}$.

Antigen-specific proliferation was assessed in PBMC cultures $\left(1.10^{6} \mathrm{PBMC} / \mathrm{ml}\right.$ in $10 \%$ autologous plasma) at baseline and week 10. Cells were incubated in quadruplicate cultures with tetanus toxoid (NIBSC, Hertfordshire, UK) at final concentrations of $0,1,2.5$ and $5 \mathrm{lfu} / \mathrm{ml}$ or with heat-inactivated S.typhi Ty21a cells at $0,0.1^{*} 10^{6}$, $1^{*} 10^{6}$ and $5^{*} 10^{6}$ cells $/ \mathrm{ml}$. Bacterial cells were cultured from the oral vaccine capsule (Vivotif Berna, Primmed BV, Almere, NL) by resuspending the capsule contents in sterile water and plating onto BHI agar plates for single colony isolation. An isolated colony was then expanded in Luria broth, heat inactivated and stored at $4{ }^{\circ} \mathrm{C}$ until use. Desired S.typhi Ty21a concentrations were prepared in RPMI culture medium and incubated with PBMC.

Cultures were incubated for 3 (mitogenic) or 6 days (antigen specific) at $37^{\circ} \mathrm{C}, 5 \% \mathrm{CO}_{2}$. Eighteen hours before the end of the incubation periods, $0.4 \mu \mathrm{Ci}$ methyl- ${ }^{3} \mathrm{H}$-thymidine (Amersham Pharmacia, Buckinghamshire, UK) was added per well. Incorporated ${ }^{3} \mathrm{H}$-thymidine was measured in a $\beta$-scintillationcounter (Microbeta Trilux scintillationcounter, Wallac, Turku, Finland).

\section{Statistics}

The power of the study was based on a study by Meydani et al [8]. In this study $200 \mathrm{mg} \mathrm{d}, 1-\alpha$-tocopherol increased the antibody response to tetanus toxoid vaccine 1.7 -fold $(P=0.04)$. From these data the variance of the natural log was calculated to be 0.8 . It is estimated that a difference of 1.5 would indicate a significant increase in antibody titers. In a $2 \times 2$ factorial design (with A and B as factors), 35 volunteers per group (70 per level of A or B) would be sufficient to detect a 1.53 -fold increase in response to tetanus 
toxoid vaccine (power of 0.8 , alpha $=0.05$ ). Therefore, $\mathrm{a}$ total of 140 subjects were recruited.

Data were analyzed by analysis of variance with colostrum treatment, micronutrient treatment, cohorts and gender as factors. As in none of the tested parameters a significant interaction between colostrum and micronutrient treatment was found, groups were combined to test micronutrient treatment versus no micronutrient treatment, and colostrum treatment versus no colostrum treatment. Occasionally individual datapoints were missing due to laboratory error or missing samples. The correct numbers on which statistical analyses were based are provided with the corresponding datasets.

Results are presented as least square means (LSM) with $95 \%$ confidence interval (95\% CI) for the four treatment groups. The p-values of the statistical analyses are based on the combination of the groups $(2 * 2$ factorial design). A p-value $<0.05$ was considered significant. The distributions of the response to vaccination (TT IgG and Ty21a IgG and IgA) were skewed, therefore, natural logarithmtransformed values for these variables were used for statistical testing. The delta compared to the baseline values of these parameters was expressed as a factor.

Covariance-analysis, adjusted for age, gender, treatment, cohort and interaction terms between age and treatments was used to evaluate the association between age and immune parameters. To show the effect of age, we subdivided the group in two age groups, using the median age of 56 years as cut-off point. All analysis were performed using the SAS statistical package version 8.2 (SAS institute, NC, US).

\section{Results}

\section{Composition of test products}

The average amounts of active ingredients were comparable between the individual batches, were higher than the target levels and remained stable over the time course of the study (Table 1).

\section{Baseline characteristics, randomization, and compliance} Four subjects dropped out of the study for reasons unrelated to the intervention. One of these subjects dropped out after 6 weeks, still leaving a complete data set except for the vaccination-related measurements. During a blind review 4 more volunteers were excluded from the analyses due to body weight loss $>10 \mathrm{~kg}$ during the study, number of B-cells vastly exceeding reference range, non-compliance and illness, respectively.

Characteristics of the 131 subjects included in the analysis are given in Table 2. Average BMI, age, vitamin E concentrations and response to tetanus vaccination were similar in all groups. Of the subjects completing the study $68 \%$ were women and the average age was $57 \pm 10$ years. The overall compliance was good, $92 \%$ of the volunteers consumed more than $98 \%$ of the supplied products. One person did not consume 14 packages of the total of 140 . This person was removed from the dataset in the blind review.

\section{Plasma concentrations of micronutrients}

At baseline, plasma concentrations of vitamin E \& C and $\beta$-carotene were comparable between the groups, i.e. 27 $\mu \mathrm{mol} / \mathrm{L}$ for $\alpha$-tocopherol, $\sim 0.5 \mu \mathrm{mol} / \mathrm{L}$ for $\beta$-carotene and $\sim 37 \mu \mathrm{mol} / \mathrm{L}$ for vitamin C. At week $6, \alpha$-tocopherol concentrations had increased by more than $90 \%$, vitamin $\mathrm{C}$ by more than $70 \%$ and $\beta$-carotene over $900 \%$ (to $\sim 5.7$ $\mu \mathrm{mol} / \mathrm{L}$ ) in the groups consuming the micronutrient containing drinks $(\mathrm{P}<0.001$ for all), whereas no change was observed in the two non-micronutrient groups (Figure 1). All concentrations seemed to plateau by week 6 as no further increase was observed after 10 weeks intervention. Simultaneous consumption of colostrum did not affect the concentrations of these micronutrients in plasma.

\section{Response to vaccination}

As expected, tetanus-specific IgG increased markedly after vaccination. Compared to baseline, titers were 17 -fold increased in the control group, 23-fold in micronutrient group, 27-fold in colostrum group and 37-fold in micronutrient + colostrum group 2 weeks after vaccination (week 8 of the intervention) (Table 3). However, none of the treatments significantly affected the mean titers, the percentage of vaccine-responders $(81 \%, 91 \%, 94 \%$ and $97 \%$ at week 10 for control, colostrum, micronutrient, micronutrient + colostrum, respectively), or the mean titers of the responders (data not shown).

After the oral typhus vaccination, specific IgG and IgA titers in serum were increased in all groups 2 weeks after vaccination (week 8 of the intervention) after which titers tended to decrease by 4 weeks after vaccination (week 10 of the intervention). The specific IgG antibody titers were significantly higher in the micronutrient groups compared to the non-micronutrient groups, but this significant difference was already present at baseline and could therefore not be attributed to the treatments (Table 3). Increase compared to baseline values was comparable in all groups and treatments did also not significantly affect the percentage of responders $(74 \%, 75 \%, 60 \%$ and $70 \%$ for IgG and $42 \%, 64 \%, 53 \%$ and $59 \%$ for IgA at 2 weeks after vaccination for control, colostrum, micronutrient, micronutrient + colostrum, respectively), or the mean titer of the responders (data not shown). Typhus-specific salivary IgA was only found in very few subjects and only 4 out of the 129 tested individuals could be marked as responder based on salivary IgA responses (data not shown). 
Table 2: Baseline characteristics of subjects who completed the study

\begin{tabular}{|c|c|c|c|c|c|}
\hline & Total & Control & Colostrum & Micronutrients & Micronutrients + colostrum \\
\hline \multicolumn{6}{|l|}{ Gender, $\mathrm{n}$} \\
\hline Total & $13 \mid$ & 31 & 33 & 32 & 35 \\
\hline Men & 42 & 10 & 11 & 10 & 11 \\
\hline Women & 89 & 21 & 22 & 22 & 24 \\
\hline \multicolumn{6}{|l|}{ Age, years } \\
\hline Total & $56.7 \pm 10.0$ & $56.0 \pm 10.1$ & $56.8 \pm 10.2$ & $57.5 \pm 10.1$ & $56.3 \pm 9.9$ \\
\hline Men & $61.4 \pm 10.1$ & $57.7 \pm 9.9$ & $62.4 \pm 10.9$ & $61.9 \pm 11.4$ & $63.4 \pm 8.5$ \\
\hline Women & $54.4 \pm 9.2$ & $55.2 \pm 10.3$ & $54.1 \pm 8.9$ & $55.5 \pm 9.1$ & $53.0 \pm 8.8$ \\
\hline \multicolumn{6}{|l|}{$\mathrm{BMI}, \mathrm{kg} / \mathrm{m}^{2}$} \\
\hline Total & $25.3 \pm 2.7$ & $25.1 \pm 3.2$ & $25.4 \pm 2.50$ & $24.9 \pm 2.5$ & $25.6 \pm 2.5$ \\
\hline Men & $26.0 \pm 2.6$ & $26.5 \pm 3.4$ & $26.0 \pm 2.3$ & $26.0 \pm 2.3$ & $25.5 \pm 2.5$ \\
\hline Women & $24.9 \pm 2.7$ & $24.5 \pm 3.1$ & $25.1 \pm 2.6$ & $24.3 \pm 2.5$ & $25.6 \pm 2.5$ \\
\hline \multicolumn{6}{|c|}{ Vitamin $E, \mu \mathrm{mol} / \mathrm{L}$} \\
\hline Total & $27.1 \pm 7.2$ & $27.3 \pm 10.0$ & $27.9 \pm 6.3$ & $26.9 \pm 4.5$ & $26.4 \pm 7.2$ \\
\hline Men & $28.1 \pm 9.7$ & $33.6 \pm 13.7$ & $24.5 \pm 6.6$ & $25.8 \pm 3.8$ & $28.9 \pm 10.5$ \\
\hline Women & $26.6 \pm 5.6$ & $24.3 \pm 6.0$ & $29.6 \pm 5.6$ & $27.4 \pm 4.7$ & $25.3 \pm 4.9$ \\
\hline \multicolumn{6}{|c|}{ Tetanus titers, IU/L } \\
\hline Total' & - & $\begin{array}{c}126 \\
(90.2-175)\end{array}$ & $\begin{array}{c}154 \\
(|I|-2 \mid 2)\end{array}$ & $\begin{array}{c}147 \\
(105-206)\end{array}$ & $\begin{array}{c}138 \\
(101-189)\end{array}$ \\
\hline
\end{tabular}

Data are represented as mean \pm SD

I Tetanus titers were determined at the screening examination, mean $(95 \% \mathrm{Cl})$

\section{DTH-response}

The DTH response measured as the number of positive indurations increased in all groups. In the micronutrient group the average number $(+\mathrm{CI})$ increased from 1.05 $(0.72-1.38)$ to $1.73(1.28-2.18)$ at week 6 , in the micronutrient +colostrum group from $1.11(0.80-1.42)$ to $1.62(1.20-2.04)$, in the colostrum group from 1.00 $(0.68-1.31)$ to $1.33(0.91-1.76)$ and in the control group from $0.73(0.39-1.06)$ to $0.85(0.39-1.30)$. Both the absolute values at week 6 as well as the increase compared to baseline, were significantly different between the micronutrient and the non-micronutrient groups ( $\mathrm{p}=$ 0.009 and $\mathrm{p}=0.031$, respectively).

The cumulative induration diameter tended to increase in all groups although neither the absolute values at week 6 nor the increases compared to baseline were significantly different between the micronutrient and the non-micronutrient groups $(\mathrm{p}=0.068$ and $\mathrm{p}=0.16$ respectively).

Covariance-analysis, adjusted for age, gender, cohort, treatment and interaction terms between age and treatment, indicated a positive association between DTH response and age. To show this association, we subdivided the group in two age groups, using the median age of 56 years as cut-off point. Both the number of positive indurations and the cumulative induration diameter were significantly different between the micronutrient group and the non-micronutrient group in the older age group with $\mathrm{p}<0.05$ but not in the younger (see Figure 2 ).

\section{Leukocyte subsets}

A small but significant $(\mathrm{p}<0.05)$ decrease in the percentage of B cells was observed at 10 weeks in the micronutrient-groups compared to the non-micronutrient groups (LSM (CI) for control, colostrum, micronutrient, micronutrient + colostrum were 14.6 (12.9-16.4), 13.2 (11.515.0), 11.8 (10.0-13.6), 12.1(10.4-13.8), respectively). As there were no related observations made, the biological relevance of this observation is unclear and we therefore regard this as an incidental finding. Changes in all other leukocyte populations, i.e. total leukocytes, T cells, helper $\mathrm{T}$ cells, cytotoxic/suppressor T cells, NK cells and NK-T cells were limited and did not differ between groups, either in absolute numbers or percentages (data not shown). The observed values were well within normal ranges.

\section{Phagocytosis and oxidative burst}

Consumption of colostrum and/or micronutrient-containing test products did not affect the percentage of phagocyting granulocytes when whole blood taken from these subjects was ex vivo stimulated with non-opsonised or opsonised $E$ coli, nor did it affect phagocyting activity per cell as indicated by the mean fluorescence (Table 4). Retrospective power calculation indicated that the study had sufficient power to allow detection of changes in phagocyting granulocytes of $>4 \%$. The oxidative burst in the phagocyte population as elicited by an E. coli -challenge, was also not affected (data not shown). 

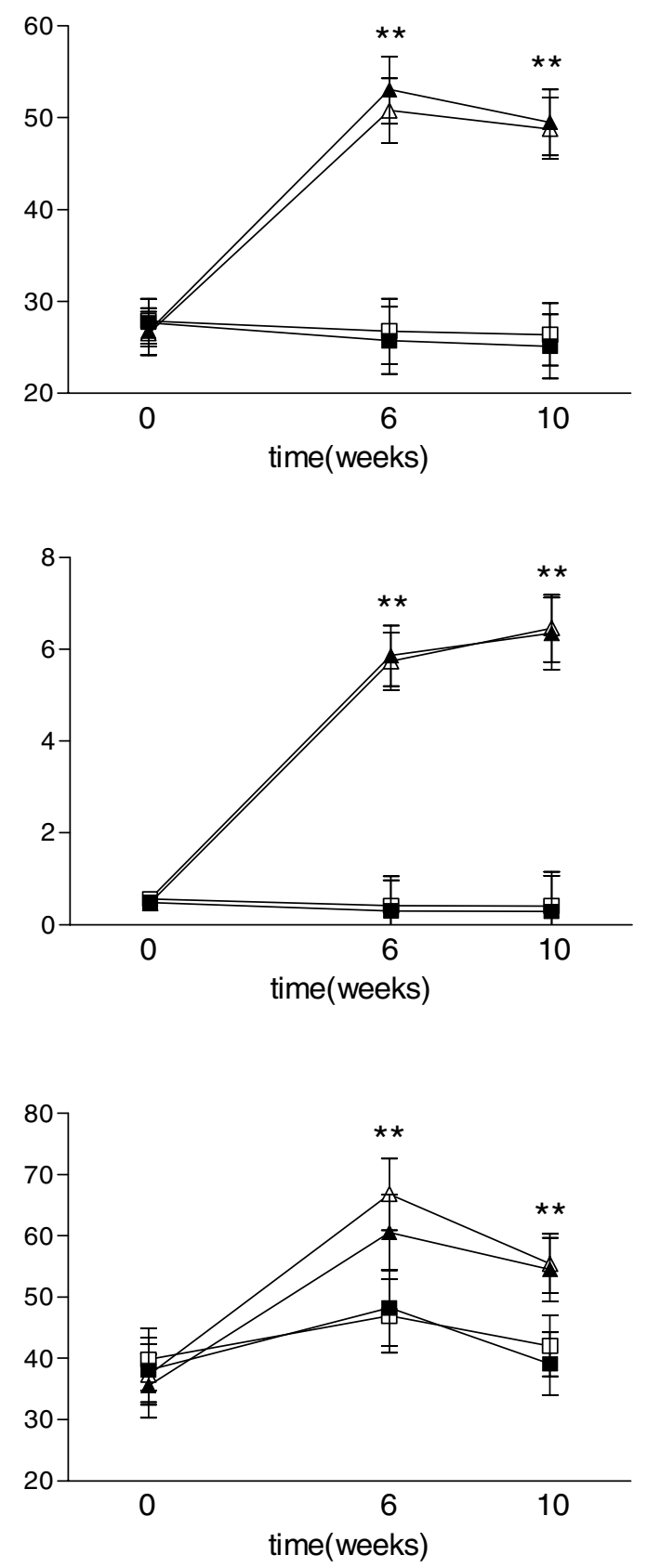

Figure I

Plasma concentrations of vitamin $C \& E$ and $\beta$-carotene. Plasma concentrations of vitamin $C \& E$ and $\beta$-carotene were measured at base line, 6 and 10 weeks. Data are expressed as LSM $( \pm 95 \% \mathrm{Cl})$. Levels in the micronutrient groups (micronutrient group $\boldsymbol{\Delta}$ and micronutrient + colostrum group $\triangle$ ) are significantly different from levels in nonvitamin group (control $\mathbf{\square}$ and colostrum group $\square$ ) with ${ }^{* *} p$ $<0.0001$.

\section{Lymphocyte proliferation}

Whole blood cultures stimulated with the mitogenic stimulus anti-CD3/CD28 demonstrated the expected relationship between stimulus concentration and proliferative response. A few significant differences were observed between the groups, but these were already apparent at baseline and the treatments did not affect the mitogenic proliferative responses as assessed at week 6 (data not shown). Stimulation of PBMC cultures with tetanus toxoid indicated the expected increase in responsiveness following the tetanus vaccination (at 4 weeks after vaccination compared to baseline), but the responses were not affected by the treatments (not shown). In contrast, proliferation induced by S.typhi Ty21a cells did not increase after vaccination. Already at baseline, proliferative responses increased with increasing concentration of S.typhi Ty21a cells, but these responses did not increase after typhoid vaccination and were also not affected by the treatments (not shown).

\section{Discussion}

Out of the range of immune function parameters examined, only the DTH response was positively affected by micronutrient intervention, whereas none of the immune parameters were affected by consumption of bovine colostrum. Separate analyses of older versus younger subjects, demonstrated that both DTH parameters, i.e. number of positive responses and diameter of indurations, were significantly enhanced in the older population, whereas this effect was not observed in the younger population.

The evidence for a positive effect of micronutrient supplementation on DTH seems to be consistent. Other studies have demonstrated an increase in the DTH response of elderly after micronutrient supplementation, especially by vitamin $\mathrm{E}[8,9]$. Also $\beta$-carotene, although in higher doses, has been described to have stimulating effects on DTH [27].

How and if an enhanced DTH response relates to improved resistance remains to be elucidated. Studies suggest a correlation between a low DTH score and risk of e.g. diarrhoeal disease in Kenyan children [28] septic-related deaths in surgical patients [29] pneumonia in elderly [30] and progression to AIDS in HIV positive individuals [31]. Interestingly, despite the more or less consistent observation that vitamin E improves the DTH response, conflicting reports were published on the effect of vitamin $E$ on resistance to respiratory infections. One study showed that consumption of $200 \mathrm{mg}$ vitamin E daily for 15 months does not improve resistance to acute respiratory tract infections [32]. In fact, it was shown that the severity of respiratory tract infection was worse in vitamin E supplemented groups, as well as the duration of the symp- 
Table 3: response to tetanus and typoid vaccination

\begin{tabular}{|c|c|c|c|c|}
\hline & Control $(n=3 I)$ & Colostrum $(n=33)$ & Micronutrients $(n=3 I)$ & Colostrum+Micronutrients $(n=35)^{2}$ \\
\hline \multicolumn{5}{|c|}{ Tetanus toxoid-specific lgG levels in serum (IU/L) } \\
\hline Baseline & $126(90.2-175)$ & $154(111-212)$ & $147(105-206)$ & $138(101-189)$ \\
\hline Week 8 & $2141(1040-4407)$ & $4074(2024-8200)$ & $3368(1625-6982)$ & $5131(2579-10208)$ \\
\hline Week 10 & $3138(17 \mid 3-5748)$ & $4728(2629-8500)$ & $4206(2282-7753)$ & $5330(3013-9431)$ \\
\hline \multicolumn{5}{|c|}{ S. typhi Ty2 I a LPS-specific IgG in serum (E.U/mL) } \\
\hline Baseline ${ }^{3}$ & $3.37(2.24-5.07)$ & $3.93(2.64-5.84)$ & $5.39(3.54-8.20)$ & $6.48(4.40-9.52)$ \\
\hline Week $8^{3}$ & $12.6(9.02-17.6)$ & $16.5(12.0-22.8)$ & $19.5(13.9-27.5)$ & $21.6(15.7-29.6)$ \\
\hline Week $10^{3}$ & $10.7(7.67-14.8)$ & $14.0(10.1-19.2)$ & $16.7(11.9-23.4)$ & $18.4(13.5-25.2)$ \\
\hline \multicolumn{5}{|c|}{ S. typhi Ty2 I a LPS-specific IgA in serum (E.U./mL) } \\
\hline Baseline & $1.21(0.85-1.72)$ & $\mathrm{I} .07(0.76-\mathrm{I} .5 \mathrm{I})$ & $1.36(0.95-1.95)$ & $1.43(1.03-1.99)$ \\
\hline Week 8 & $2.70(1.89-3.86)$ & $3.40(2.40-4.81)$ & $3.49(2.42-5.04)$ & $3.73(2.65-5.24)$ \\
\hline Week 10 & $1.80(1.29-2.52)$ & $1.86(1.35-2.57)$ & $2.24(1.59-3.14)$ & $2.20(1.60-3.01)$ \\
\hline
\end{tabular}

I values are expressed as Ismeans $(95 \% \mathrm{Cl})$.

$2 \mathrm{n}=34$ in serum at week $8, n=33$ for saliva at week 8 .

3 Micronutrient group (Micronutrients group and Colostrum + Micronutrients group) is significantly different from non-micronutrient group (Control group and Colostrum group) $(\mathrm{P}<0.05)$.

toms. A second study by Meydani et al [33] reported a protective effect of 200 IU daily of vitamin $\mathrm{E}$ for 1 year on upper respiratory tract infections, especially the common cold. How these observations correlate with respect to enhanced DTH after vitamin E suppletion remains elusive. Accumulation of vitamin $\mathrm{E}$ in tissues may account for detrimental effects of vitamin $\mathrm{E}$ and vitamin-E associated enhanced immune reactivity could either account for worsening of symptoms or improvement of resistance to certain infections. Alternatively, the DTH reaction may be an immunological parameter that is not associated with resistance to respiratory infections.

The absence of positive effects of the micronutrient mix on other immune parameters or of the colostrum preparation on all parameters examined, may largely be explained by the generally good health and nutritional status of the subjects. This is illustrated by the fact that successful immune enhancement is generally achieved in populations with suboptimal immune function such as elderly and athletes [34]. Interestingly, in elderly that retain a good nutritional status, decline in immne fucntion is not apparent $[35,36]$.

In our study population the average baseline concentrations of plasma vitamin $\mathrm{E}$, vitamin $\mathrm{C}$ and $\beta$-carotene as well as the post-intervention vitamin $\mathrm{E}$ and $\mathrm{C}$ levels were comparable to what has been described in other studies $[8,11,27,32,37]$ and are indicative for a generally wellnourished population. The observed $900 \%$ rise in plasma $\beta$-carotene, which is higher than reported increases of $300-600 \%$ in other studies using similar doses $[11,37,38]$, may be explained by the fact that the test products contained the emulsifier lecithin in a molar ratio of $\sim 70$ relative to $ß$-carotene. Emulsifiers and fat from the formulation can help form micelles, which are required for absorption of carotenoids during lipolysis, thereby improving the bioavailabilty of lipophilic molecules such as ß-carotene [39-42].

Also in the older subpopulation a lower nutritional status can not explain the observed benefit, since baseline micronutrient concentrations were higher (vitamin $\mathrm{E}$ ) or similar (vitamin $\mathrm{C}$ and $\exists$-carotene) in the subjects older than 56 years compared to the younger subjects $(29.1 \pm$ $7.6 \mathrm{umol} / \mathrm{L}$ vs $25.1 \pm 6.2 \mathrm{umol} / \mathrm{L}, \mathrm{P}=0.0012$ for vitamin E). Similarly, the size of the increase in micronutrient levels did not seem to correlate with the effect on the DTH since increases were similar in both populations.

Despite a few publications indicating the stimulatory effect of colostrum on phagocytic activity in vitro $[22,23,43]$, which we confirmed with human leukocytes (data not shown), daily consumption of $1.2 \mathrm{~g}$ of bovine colostrum concentrate by volunteers in the current study did not affect ex-vivo phagocytic activity. Similarly, none of the other investigated immune parameters were significantly influenced by colostrum consumption, although the response to tetanus vaccination tended to be somewhat higher $(\mathrm{p}=0.14)$.

Three studies have reported effects on immune function and resistance to infections after consumption of natural colostrum (enhanced response to oral typhoid vaccine [24], reduced number of URTI symptoms [44], and increased salivary IgA [45]). However, the doses of colostrum used in these studies were up to $60 \mathrm{~g} /$ day. These high doses may be feasible in the context of severe physical exercise for which some of these studies were designed or for clinical nutrition, but for daily consumption by healthy consumers only lower doses would be economically feasible. 
A) Increase in mean number of positive responses
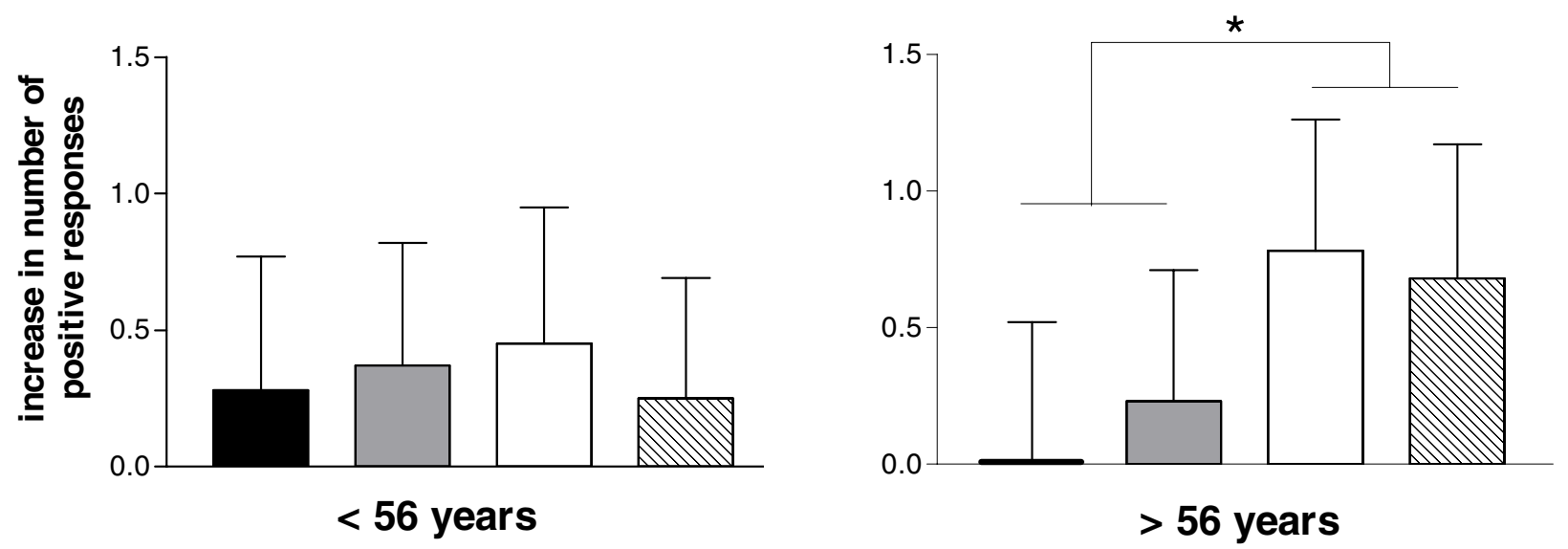

B) Increase in cumulative induration diameter
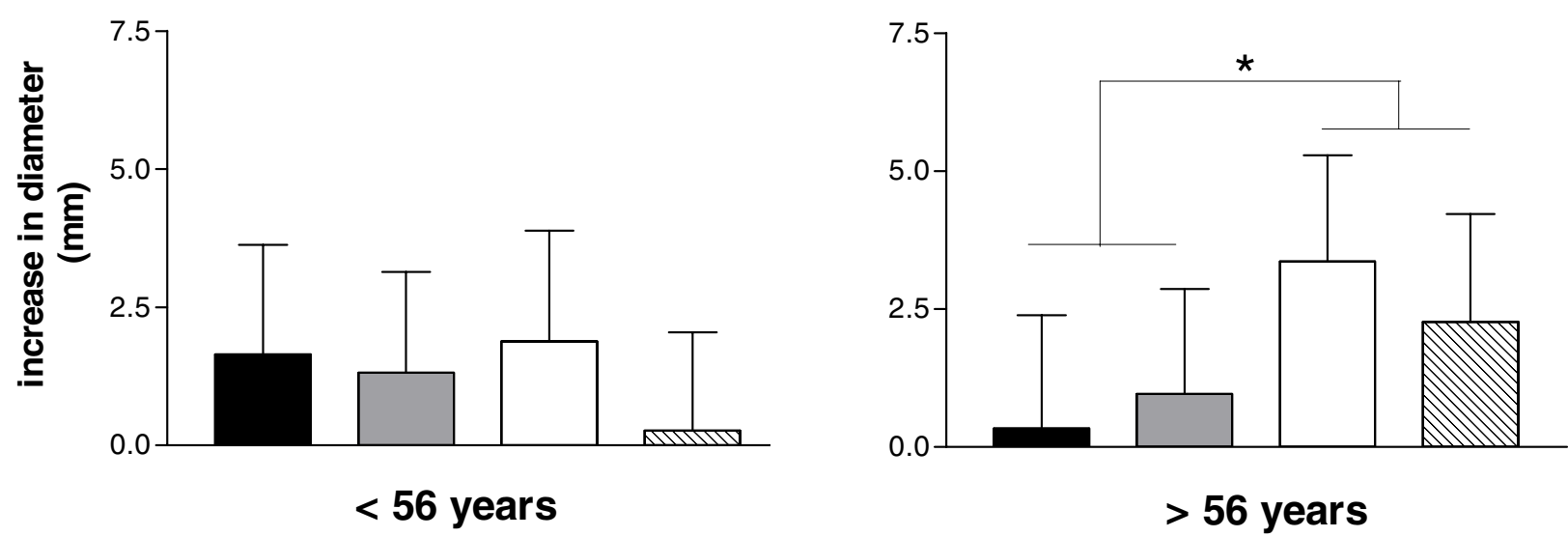

Figure 2

Delayed-type hypersensitivity response in two age groups. DTH responses were assessed using the CMI multitest at baseline and at 6 weeks. Because of significant interaction between age and treatment group $(p<0.05)$, the population was split around the median age of $56 y$ in younger $(<56 y)$ and older $(>56 y)$ subjects. Average age of the younger subjects was $48 \pm 4$ $y$, with a BMI of $24.5 \pm 2.8$, comprising 12 men and 52 women. The average age of the older subjects was $65 \pm 6 y$, with a BMI of $26.0 \pm 2.3$, comprising of 30 men and 36 women. Both age categories were evenly spread over the treatments with $15-19$ subjects per treatment per age category. Data are reported as LSM of the mean increase in the number of positive responses (A) and increase of the cumulative diameter of the positive responses (B). Responses in the micronutrient groups (micronutrient (white) and micronutrient + colostrum group (hatched)) are significantly different from levels in non-vitamin group (control (black) and colostrum group (grey)) with $* \mathrm{p}<0.05$.

\section{Conclusion}

Low daily doses of bovine colostrum do not improve a series of immune function parameters in healthy volunteers. Micronutrient suppletion of vitamins E \& C, ß-carotene and zinc positively affect the DTH response, especially in elderly subjects. How this may relate to improved resistance remains to be elucidated. Improvement of other immune parameters in individuals with a generally good immune and nutritional status may be difficult and it may take individuals with (moderately) impaired immune function to benefit from this type of nutritional intervention.

\section{Competing interests}

All authors are employed by Unilever who financed the study and publication. 
Table 4: phagocytosis of opsonized E coli

\begin{tabular}{|c|c|c|c|c|}
\hline & Control $(n=3 I)$ & Colostrum $(n=33)$ & Micronutrients $(n=31)$ & Colostrum + Micronutrients $(n=35)$ \\
\hline \multicolumn{5}{|c|}{ Granulocytes (\% of leukocytes) } \\
\hline Baseline & $47.9(44.5-51.2)$ & $49.1(45.8-52.3)$ & $49.7(46.3-53.0)$ & $52.4(49.3-55.6)$ \\
\hline Week 6 & $49.5(46.3-52.7)$ & $49.5(46.4-52.6)$ & $50.0(46.8-53.3)$ & $50.4(47.3-53.4)$ \\
\hline Difference week 0-6 & $1.63(-1.4-4.7 I)$ & $0.45(-2.5-3.43)$ & $0.39(-2.7-3.49)$ & $-2.1(-4.9-0.84)$ \\
\hline \multicolumn{5}{|c|}{ Positive granulocytes (\% of total granulocytes) } \\
\hline Baseline & $65.6(62.5-68.6)$ & $63.1(60.2-66.0)$ & $64.9(61.8-67.9)$ & $65.2(62.4-68.1)$ \\
\hline Week 6 & $60.4(57.2-63.6)$ & $58.4(55.3-6 \mid .5)$ & $56.7(53.4-59.9)$ & $58.0(55.0-61.0)$ \\
\hline Difference week 0-6 & $-5.1(-8.7--1.6)$ & $-4.7(-8.2--1.2)$ & $-8.2(-12--4.6)$ & $-7.2(-11--3.8)$ \\
\hline \multicolumn{5}{|c|}{ Granulocytes fluorescence mean } \\
\hline Baseline & $422(393-45 I)$ & $390(362-4 \mid 8)$ & $410(381-439)$ & $408(381-435)$ \\
\hline Week 6 & $450(423-478)$ & $438(4 I I-465)$ & $407(379-436)$ & $430(404-456)$ \\
\hline Difference week 0-6 & $28.7(-5.8-63.2)$ & $47.9(\mid 4.5-8 I .3)$ & $-2.6(-37-32.3)$ & $21.6(-1 I-54.1)$ \\
\hline
\end{tabular}

I values are expressed as Ismeans $(95 \% \mathrm{Cl})$

\section{Authors' contributions}

DW, ML, RvdW and RA contributed to the study design. DW and ML were responsible for the human intervention study. DW, WH and RA supervised the assays and analyzed the data. DW and WH drafted the initial manuscript and DW and RA edited the final manuscript with contributions of all the authors. All authors read and approved the final manuscript.

\section{Acknowledgements}

The authors thank the volunteers for their enthusiastic participation in the study.

The valuable discussions with Drs. R.A. Hoerr and E.F. Bostwick from Galagen Inc. on the study design are kindly appreciated. Furthermore, we thank numerous colleagues from the Unilever Health Institute for their help in the clinical and analytical phase of this study, A. Wiersma and $\mathrm{H}$. van der Knaap for statistical analysis, $\operatorname{Dr} \mathrm{G}$. Duchateau for helpful discussions on the bioavailability of carotenoids and M. Jaekel (MD) for study management and medical supervision.

\section{References}

I. Field CJ, Johnson IR, Schley PD: Nutrients and their role in host resistance to infection. J Leukoc Biol 2002, 71 : I6-32.

2. de la Fuente M, Ferrandez MD, Burgos MS, Soler A, Prieto A, Miquel $\mathrm{J}$ : Immune function in aged women is improved by ingestion of vitamins C and E. Can J Physiol Pharmacol 1998, 76:373-380.

3. Jayachandran M, Rani PJA, Arivazhagan P, Panneerselvam C: Neutrophil phagocytic function and humoral immune response with reference to ascorbate supplementation in aging humans. JOURNAL OF ANTI-AGING MEDICINE 2000, 3:37.

4. Anderson R, Oosthuizen R, Maritz R, Theron A, Van Rensburg AJ: The effects of increasing weekly doses of ascorbate on certain cellular and humoral immune functions in normal volunteers. Am J Clin Nutr 1980, 33:7I-76.

5. Nieman DC, Henson DA, Butterworth DE, Warren BJ, Davis JM, Fagoaga OR, Nehlsen-Cannarella SL: Vitamin C supplementation does not alter the immune response to $\mathbf{2 . 5}$ hours of running. International Journal Of Sport Nutrition 1997, 7:173-184.

6. Delafuente JC, Prendergast JM, Modigh A: Immunologic modulation by vitamin C in the elderly. Int J Immunopharmacol 1986, 8:205-2II.

7. Nieman DC, Henson DA, McAnulty SR, McAnulty L, Swick NS, Utter AC, Vinci DM, Opiela SJ, Morrow JD: Influence of vitamin C supplementation on oxidative and immune changes after an ultramarathon. J Appl Physiol 2002, 92: 1970- 1977.
8. Meydani SN, Meydani M, Blumberg JB, Leka LS, Siber G, Loszewski R, Thompson C, Pedrosa MC, Diamond RD, Stollar BD: Vitamin E supplementation and in vivo immune response in healthy elderly subjects. A randomized controlled trial. JAMA 1997, 277:1380-1386

9. Pallast EG, Schouten EG, De Waart FG, Fonk HC, Doekes G, von Blomberg BM, Kok FJ: Effect of 50- and $100-\mathbf{m g}$ vitamin $E$ supplements on cellular immune function in noninstitutionalized elderly persons. Am J Clin Nutr 1999, 69:1273-128I.

10. Chew BP, Park JS: Carotenoid action on the immune response. J Nutr 2004, 134:257S-26IS.

II. Santos MS, Meydani SN, Leka L, Wu D, Fotouhi N, Meydani M, Hennekens $\mathrm{CH}$, Gaziano JM: Natural killer cell activity in elderly men is enhanced by beta- carotene supplementation. $\mathrm{Am} \mathrm{J}$ Clin Nutr 1996, 64:772-777.

12. Santos MS, Gaziano JM, Leka LS, Beharka AA, Hennekens CH, Meydani SN: Beta-carotene-induced enhancement of natural killer cell activity in elderly men: an investigation of the role of cytokines. Am J Clin Nutr 1998, 68: 164-I70.

13. Santos MS, Leka LS, Ribaya-Mercado JD, Russell RM, Meydani M, Hennekens CH, Gaziano JM, Meydani SN: Short- and long-term betacarotene supplementation do not influence T cell-mediated immunity in healthy elderly persons. Am J Clin Nutr 1997, 66:917-924.

14. Bogden JD, Oleske JM, Lavenhar MA, Munves EM, Kemp FW, Bruening KS, Holding KJ, Denny TN, Guarino MA, Krieger LM: Zinc and immunocompetence in elderly people: effects of zinc supplementation for 3 months. Am J Clin Nutr 1988, 48:655-663.

15. Bogden JD, Oleske JM, Lavenhar MA, Munves EM, Kemp FW, Bruening KS, Holding KJ, Denny TN, Guarino MA, Holland BK: Effects of one year of supplementation with zinc and other micronutrients on cellular immunity in the elderly. J Am Coll Nutr 1990, 9:214-225.

16. Fortes C, Forastiere F, Agabiti N, Fano V, Pacifici R, Virgili F, Piras G, Guidi L, Bartoloni C, Tricerri A, Zuccaro P, Ebrahim S, Perucci CA: The effect of zinc and vitamin $A$ supplementation on immune response in an older population. J Am Geriatr Soc 1998, 46:19-26.

17. Duchateau J, Delepesse G, Vrijens R, Collet $\mathrm{H}$ : Beneficial effects of oral zinc supplementation on the immune response of old people. Am J Med 1981, 70:1001-1004.

18. Provinciali M, Montenovo A, Di Stefano G, Colombo M, Daghetta L, Cairati M, Veroni C, Cassino R, Della TF, Fabris N: Effect of zinc or zinc plus arginine supplementation on antibody titre and lymphocyte subsets after influenza vaccination in elderly subjects: a randomized controlled trial. Age Ageing 1998, 27:715-722.

19. Playford RJ, Macdonald CE, Johnson WS: Colostrum and milkderived peptide growth factors for the treatment of gastrointestinal disorders. Am J Clin Nutr 2000, 72:5-14.

20. Gill HS, Doull F, Rutherfurd KJ, Cross ML: Immunoregulatory peptides in bovine milk. Br J Nutr 2000, 84 SuppI I:SIII-SII 7. 
21. Korhonen H, Marnila P, Pihlanto LA, Ryhanen EL: Bioactive components of milk: natural ingredients for health promotion. Innovations-in-Food-Technology; 2001, 1 0:23-27.

22. Sugisawa H, Itou T, Sakai T: Promoting effect of colostrum on the phagocytic activity of bovine polymorphonuclear leukocytes in vitro. BIOLOGY OF THE NEONATE 200I, 79: 140.

23. Loimaranta $\bigvee$, Nuutila J, Marnila $P$, Tenovuo J, Korhonen $H$, Lilius EM Colostral proteins from cows immunised with Streptococcus mutans/S. sobrinus support the phagocytosis and killing of mutans streptococci by human leucocytes. J Med Microbiol 1999, 48:917-926.

24. He F, Tuomola E, Arvilommi H, Salminen S: Modulation of human humoral immune response through orally administered bovine colostrum. FEMS IMMUNOLOGY AND MEDICAL MICROBIOLOGY 200I, 3 I:93.

25. Albers R, Antoine JM, Bourdet-Sicard R, Calder PC, Gleeson M, Lesourd B, Samartin S, Sanderson IR, Van Loo J, Vas Dias FW, Watzl $B$ : Markers to measure immunomodulation in human nutrition intervention studies. $\mathrm{Br} J$ Nutr 2005, 94:452-48I.

26. Viret JF, Favre D, Wegmuller B, Herzog C, Que JU, Cryz SJ Jr., Lang $A B$ : Mucosal and systemic immune responses in humans after primary and booster immunizations with orally administered invasive and noninvasive live attenuated bacteria. Infect Immun 1999, 67:3680-3685.

27. Herraiz LA, Hsieh WC, Parker RS, Swanson JE, Bendich A, Roe DA: Effect of UV exposure and beta-carotene supplementation on delayed-type hypersensitivity response in healthy older men. J Am Coll Nutr 1998, I 7:617-624.

28. Shell-Duncan B, Wood JW: The evaluation of delayed-type hypersensitivity responsiveness and nutritional status as predictors of gastro-intestinal and acute respiratory infection: a prospective field study among traditional nomadic Kenyan children. J Trop Pediatr 1997, 43:25-32.

29. Christou NV, Tellado-Rodriguez J, Chartrand L, Giannas B, Kapadia $\mathrm{B}$, Meakins J, Rode H, Gordon J: Estimating mortality risk in preoperative patients using immunologic, nutritional, and acute-phase response variables. Ann Surg 1989, 21 0:69-77.

30. Nakayama K, Monma M, Fukushima T, Ohrui T, Sasaki H: Tuberculin responses and risk of pneumonia in immobile elderly patients. Thorax 2000, 55:867-869.

31. Blatt SP, Hendrix CW, Butzin CA, Freeman TM, Ward WW, Hensley RE, Melcher GP, Donovan DJ, Boswell RN: Delayed-type hypersensitivity skin testing predicts progression to AIDS in HIV infected patients. Ann Intern Med 1993, I I 9: I77- I84.

32. Graat JM, Schouten EG, Kok FJ: Effect of daily vitamin e and multivitamin-mineral supplementation on acute respiratory tract infections in elderly persons: a randomized controlled trial. JAMA 2002, 288:7I5-72I

33. Meydani SN, Leka LS, Fine BC, Dallal GE, Keusch GT, Singh MF, Hamer DH: Vitamin $E$ and respiratory tract infections in elderly nursing home residents: a randomized controlled trial. JAMA 2004, 292:828-836.

34. Hamer M, Wolvers D, Albers R: Using stress models to evaluate immuno-modulating effects of nutritional intervention in healthy individuals. J Am Coll Nutr 2004, 23:637-646.

35. Ahluwalia N, Mastro AM, Ball R, Miles MP, Rajendra R, Handte G: Cytokine production by stimulated mononuclear cells did not change with aging in apparently healthy, well-nourished women. Mech Ageing Dev 200I, I 22:1269-I279.

36. Krause D, Mastro AM, Handte G, Smiciklas-Wright H, Miles MP, Ahluwalia N: Immune function did not decline with aging in apparently healthy, well-nourished women. Mech Ageing Dev 1999, I I 2:43-57.

37. Daudu PA, Kelley DS, Taylor PC, Burri BJ, Wu MM: Effect of a low beta-carotene diet on the immune functions of adult women. Am J Clin Nutr 1994, 60:969-972.

38. Hughes DA, Wright AJ, Finglas PM, Peerless AC, Bailey AL, Astley SB Pinder AC, Southon S: The effect of beta-carotene supplementation on the immune function of blood monocytes from healthy male nonsmokers. I Lab Clin Med I997, I 29:309-3 I 7.

39. A.J. H, W.N. C: Lipi-based vehicles for the oral delivery of poorly water soluble drugs. Advanced Drug Delivery Reviews 1997, 25: $103-128$

40. MacGregor KJ, Embleton JK, Lacy JE: Influence of lipolysis on drug absorption from the gastrointestinal tract. Advanced Drug Delivery Reviews 1997, 25:33-46.
4I. O'Driscoll CM: Lipid-based formulations for intestinal lymphatic delivery. Eur J Pharm Sci 2002, I 5:405-4I5.

42. Pouton CW: Lipid formulations for oral administration of drugs: non-emulsifying, self-emulsifying and 'self-microemulsifying' drug delivery systems. Eur J Pharm Sci 2000, I I Suppl 2:S93-S98.

43. Sugisawa $H$, Itou $T$, Ichimura $Y$, Sakai $T$ : Bovine milk enhances the oxidative burst activity of polymorphonuclear leukocytes in low concentrations. J Vet Med Sci 2002, 64: I I I 3- I I I6.

44. Brinkworth GD, Buckley JD: Concentrated bovine colostrum protein supplementation reduces the incidence of selfreported symptoms of upper respiratory tract infection in adult males. Eur J Nutr 2003, 42:228-232.

45. Mero A, Miikkulainen H, Riski J, Pakkanen R, Aalto J, Takala T: Effects of bovine colostrum supplementation on serum IGF-I, IgG, hormone, and saliva IgA during training. J Appl Physiol 1997, 83: I|44-||5|.

Publish with Bio Med Central and every scientist can read your work free of charge

"BioMed Central will be the most significant development for disseminating the results of biomedical research in our lifetime. "

Sir Paul Nurse, Cancer Research UK

Your research papers will be:

- available free of charge to the entire biomedical community

- peer reviewed and published immediately upon acceptance

- cited in PubMed and archived on PubMed Central

- yours - you keep the copyright

Submit your manuscript here:

http://www.biomedcentral.com/info/publishing_adv.asp
BioMedcentral 